\title{
The situation of Covid-19 outbreak in Turkish Republic of Northern Cyprus, during the time of pandemic fatigue
}

\author{
Emine Unal Evren ${ }^{1}$, Hakan Evren ${ }^{1 *}$,
}

\begin{abstract}
The coronavirus disease 2019 (COVID-19) outbreak has caused a massive impact on the entire world. Healthcare systems, economies, and social lives have already been overwhelmed. Turkish Republic of Northern Cyprus (TRNC), having been COVIDfree for around two and a half months in the middle of the pandemic, is now facing a second wave of the infection after easing its preventive measures. Early implementation of precautions may dramatically reduce COVID-19 infections, but the virus is not eliminated. Additionally, the phenomenon "pandemic fatigue" introduced by the WHO is contributing to a significant decline in compliance with mitigation behaviors globally. With vaccines now rolling out, there is a reason to hope that there is an end in sight; however, it will most likely take a half year for widespread vaccinations to be in place. Decision-makers should analyze the effects of each intervention and pandemic fatigue to get ready for the further waves of infection.
\end{abstract}

Keywords: COVID-free, Second wave, Containment, Pandemic fatigue

Main points: TRNC became COVID- free after implementing the control measures in response to the pandemic immediately. However, relaxing the measures ended up in new cases. Thinking about easing the preventive measures during the time of pandemic fatigue should be rigorously analyzed, and detailed plans should be formulated to ensure the physical and mental safety of the population before.

${ }^{1}$ University of Kyrenia, Faculty of Medicine, Department of Infectious Diseases and Clinical Microbiology, Kyrenia, Turkish Republic of Northern Cyprus

*Corresponding Author:

Hakan Evren, Asst Prof Dr

Orcid ID: 0000-0001-8247-8144

Mailing address: University of Kyrenia Dr. Suat

Gunsel Hospital, Department of Infectious Diseases

and Clinical Microbiology, Kyrenia, Turkish Republic of Northern Cyprus

E-mail: hakan.evren@med.kyrenia.edu.tr

Phone: +903926502693/+905338837200

DOI: 10.2478/ebtj-2021-0014

(๑) 2021 Authors. This work was licensed under the

Creative Commons Attribution-NonCommercial-

NoDerivs 4.0 License.

\section{Introduction}

The world has been facing an unexpected pandemic challenge since December 2019. By 28 February 2021, the coronavirus had caused about 113.315 .218 confirmed cases and 2.517.964 deaths globally (1). Border control measures, together with isolation and quarantine policies implemented in response to COVID-19, have made it possible for many countries to contain the outbreak. Still, the economies were hit hard as well. The first case of COVID-19 in TRNC, a de faction-dependent republic with a population of 350000 , was identified on 9 March 2020. Following a combination of precautions taken on time by the country's council of ministers, depending on a science board's decisions, TRNC had successfully controlled the outbreak. The number of cases had been steady after the index case without exponential growth, and the country had become COVID- free for about two and a half months. However, the COVID-19 pandemic is far from over on a global scale, and cases followed by the second wave have been reported after the relaxation of the measures in TRNC. It seems that as the countries strive to reopen their economies, the possibility of COVID- 19 clusters can not be ignored, and both policymakers and health care professionals will keep dealing with those flare-ups. This study aimed to discuss the strategies and their effectiveness enacted in TRNC to limit the ongoing pandemic.

\section{Materials and Methods}

Epidemiological data were collected from available official government sources and 
SARS-CoV-2 positive cases were followed from announcements of Ministery of Health offices. Preventive measures implemented after the first reported case were analyzed for their effectiveness as control strategies.

\section{Results}

Figure 1 shows COVID-19 surveillance in TRNC between March 2020 and February 2021. Table1 shows the number of tests conducted and the situation of confirmed cases. Below are the critical precautions taken by the Council of Ministers with regard to science boards decisions in TRNC to prevent further transmission.

Table 1. Total SARS-CoV-2 cases identified in TRNC by 28 February 2021

\begin{tabular}{|c|c|}
\hline Tests conducted in total & 541,916 \\
\hline Positive cases confirmed in total & 3416 \\
\hline Patients recovered and discharged in total & 3002 \\
\hline Patients in hospital & 78 \\
\hline Patients in quarantine hotels & 310 \\
\hline Deaths in total & 23 \\
\hline
\end{tabular}

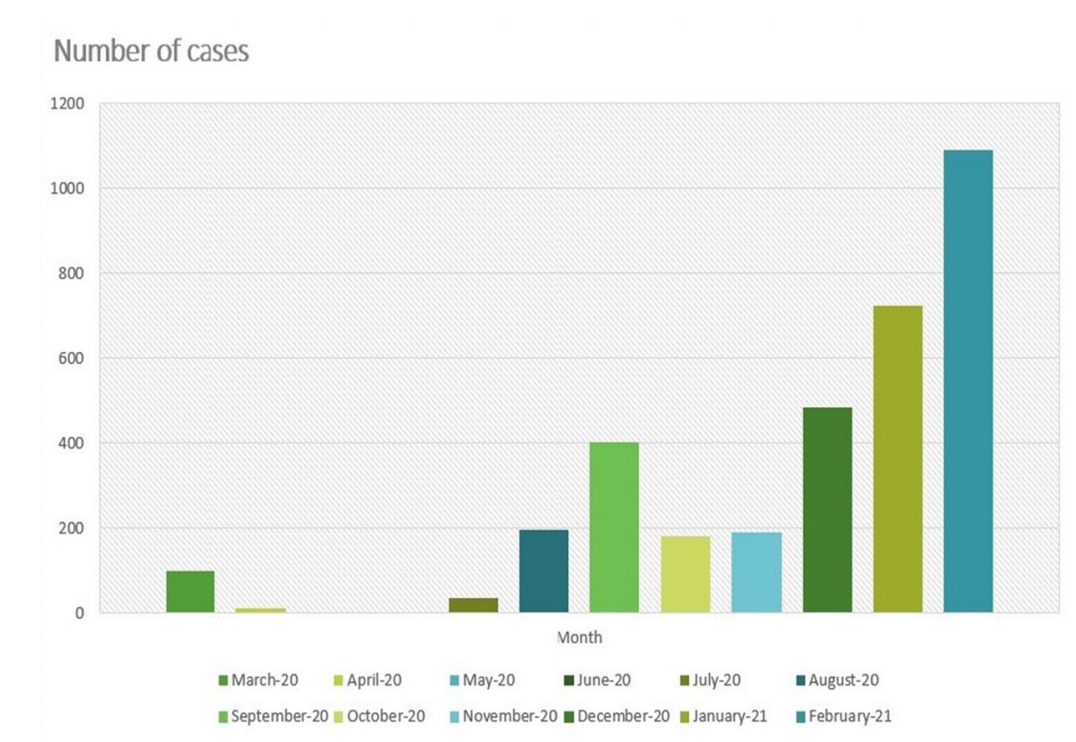

Figure 1. Monthly confirmed cases of Covid-19 in TRNC care workers, were considered on administrative leave. Gathering in associations and performing collective worship was also banned. A political curfew has been announced, and after the identification of cumulative COVID -19 cases in the same villages where the people live in close contacts, the lockdown of those villages had been put in practice. As education is the key to empower public commitment, it is done through traditional print and media and social media. The messages included information about regular hand washing, staying at home when unwell, seeking medical treatment early when needed, and rational use of personal protective equipment. Detailed statistics on COVID -19 cases were shared every day publicly.

\section{Border control measures}

In mid-February, TRNC advised its citizens to postpone non-essential travel to mainland China, Italy, the Republic of Korea, and Iran. On 14 March, entries to the country through land border gates, air, and sea transport by other country's citizens were banned. Regardless of where they come from, citizens and legal residents entering the country were considered to be quarantined at home for fourteen days. Legal action was guaranteed to be taken for those who do not comply with this requirement. Cypriot students studying abroad were brought to the country with charter flights and put in quarantine for 14

\section{Community and social measures}

All schools were closed two days after the first case, and an online education system was launched. TRNC has implemented other primary social distancing measures such as closures of restaurants, casinos, nightclubs, betting offices, and other commercial entertainment centers. The shops supplying basic needs, including pharmacies, gas stations, markets, and bakeries, remained open, and they were advised to work with the least number of staff as shifts. Besides, civil workers in the public sector, except for police, finance, fire brigade, and health- days in hotels. They were screened by rapid IgG/IgM detection tests and further by PCR using nasopharyngeal swab samples when needed. Individuals who had negative results were sent home and asked to self isolate in their home for a further seven days.

\section{Health-care measures}

Infection control measures were strengthened and revised according to COVID -19 in the hospital settings. An outpatient clinic was activated to improve the management of respiratory 
infections in primary care. Besides, a 7/24 call center reacting to both English and Turkish was announced by the ministry of health as COVID -19 reporting line. Moreover, a state hospital located in the capital city has turned into a pandemic hospital. All suspected and confirmed cases were immediately isolated in the hospital.In addition to these measures, filiation teams were established immediately. These field teams were responsible for epidemiological investigations, and contact tracing. The health-care workers of the pandemic hospital were directed to stay in hotels in order to protect their families from infection.

\section{Discussion}

In the past two decades, there have been two major coronavirus outbreaks, the SARS-CoV(2002) and the MERS-CoV(2012), that happened in China and Saudi Arabia, respectively (2). The world is now facing a situation of an outbreak with a closely related virus, COVID-19. The recent outbreak that started in China has spread to several other countries and has taken many lives. Although SARS-CoV was more pathogenic and frightening compared to COVID-19, the world was able to stop the epidemic by the implementation of traditional public health measures in the absence of vaccines and antivirals (3). Regarding the COVID-19 outbreak, there are also many encouraging examples of policy responses such as China, Vietnam, Singapore, Hong Kong, and the Republic of South Korea that might be a guidance model for other countries (4-6). On the other hand, it is well-known that COVID-19 may spread dramatically and abruptly. United States examples proved how quickly the health-care system could be blocked (7).

After the first case was reported on 9 March 2020, TRNC had reported 3416 COVID 19 cases and 23 related deaths. Immediate action and a wide range of precautions interrupted the spread of the virus, and TRNC became COVID- free 37 days after the first case. However, lockdown, curfew and, closure of commercial companies had an enormous economic impact, and the political structures were under considerable pressure as many people were already out of work. As a result, TRNC relaxed its preventive measures, which were in place for around three months. By the end of August 2020, the country was hit harder by the second wave of the pandemic. Meanwhile, the term 'pandemic fatigue' indicating the feeling of distress in the entire population as a reaction to a prolonged state of crisis was introduced by the WHO. The world was witnessing a consistent decline in compliance with mitigation behaviors, and pandemic fatigue was cited as a contributor to this phenomenon, thus increasing incidence rates all over the world (8). Although a similar containment strategy was conducted in the second wave in TRNC, the number of newly infected cases remained steady without decline. We believe that this is also something particular to emphasize in this society.

The transmission of coronavirus in TRNC was mainly driven by imported cases after relaxing the control measures. Thus we believe that border control measure was one of the most effective ongoing actions put in place around three months in TRNC. A recent study has modeled the possible adverse out- comes of early relaxation of interventions and has found that such actions might cause flare-ups in transmissibility. However, the effect of each precaution was not addressed in the study (9). Travel restrictions were found to impact delaying the epidemic progression at an international scale dramatically, but only a short delay in China (10). Thus, it is likely that country-specific models of each intervention's effects and alternative actions after relaxation are now needed.

The development of vaccines is a significant breakthrough in the fight against the COVID-19. As of February 2021, TRNC has vaccinated $15 \%$ of its population with both an inactivated and RNA-based Covid-19 vaccines (CoronoVac and Pfizer-BioNTech respectively) However, widespread vaccinations do not seem to be in place until the middle of the year at the earliest. Multiple vaccines have been approved in many countries, but the effectiveness of immunization programs remains still unknown. So, we have some ways to go, yet with nonpharmaceutical interventions such as social distancing, mask-wearing, and other mitigation behaviors. Moreover, long-term post immunization monitoring is also needed.

The future of the pandemic is hard to predict. However, the ongoing pattern and character of COVID-19 make it clear that there is a considerable probability of the next waves of the infection. The interventions TRNC implemented in response to the outbreak had a real and dramatic effect on interrupting the transmission in the beginning, but the virus is not eliminated and may remain asymptomatic in many cases without developing any severe consequences. However, these asymptomatic people will be transferring the virus to high-risk populations such as the elderly, causing more burden on the health care system, social lives, and economies(11). The probability of a false sense of security due to the roll-out of vaccines, the emergence of new variants, and the impact of pandemic fatigue are now leading us to another complicated process. These all will happen not only at a country level but also globally as the world is interconnected.

In conclusion, as the epidemic is growing exponentially, the name of the game at this point is suppression rather than elimination in all countries. Therefore the societies should maintain the highest level of alert, and the policymakers should tune the relaxation decisions timely and accordingly.

\section{References}

1. World Health Organization. WHO coronavirus disease (COVID-19) dashboard. Geneva, Switzerland: World Health Organization; 2021. https://covid19.who.int/

2. De Wit E, Van Doremalen N, Falzarano D, Munster VJ. SARS and MERS: recent insights into emerging coronaviruses. Nature Reviews Microbiology. 2016;14(8):523.

3. Wilder-Smith A, Freedman DO. Isolation, quarantine, social distancing and community containment: pivotal role for old-style public health measures in the novel coronavirus (2019-nCoV) outbreak. Journal of travel medicine. 2020;27(2):taaa020.

4. Novel CPERE. The epidemiological characteristics of an 
outbreak of 2019 novel coronavirus diseases (COVID-19) in China. Zhonghua liu xing bing xue za zhi= Zhonghua liuxingbingxue zazhi. 2020;41(2):145.

5. La V-P, Pham T-H, Ho M-T, Nguyen M-H, P Nguyen K-L, Vuong T-T, et al. Policy response, social media and science journalism for the sustainability of the public health system amid the COVID-19 outbreak: The vietnam lessons. Sustainability. 2020;12(7):2931.

6. Lee VJ, Chiew CJ, Khong WX. Interrupting transmission of COVID-19: lessons from containment efforts in Singapore. Journal of Travel Medicine. 2020;27(3):taaa039.

7. Fowler JH, Hill SJ, Levin R, Obradovich N. The effect of stay-at-home orders on COVID-19 infections in the United States. arXiv preprint arXiv:200406098. 2020.

8. Organization WH. Pandemic fatigue: reinvigorating the public to prevent COVID-19: policy framework for supporting pandemic prevention and management: revised version November 2020. World Health Organization. Regional Office for Europe; 2020.

9. Leung K, Wu JT, Liu D, Leung GM. First-wave COVID-19 transmissibility and severity in China outside Hubei after control measures, and second-wave scenario planning: a modelling impact assessment. The Lancet. 2020.

10. Chinazzi M, Davis JT, Ajelli M, Gioannini C, Litvinova $\mathrm{M}$, Merler S, et al. The effect of travel restrictions on the spread of the 2019 novel coronavirus (COVID-19) outbreak. Science. 2020;368(6489):395-400.

11. Chen N, Zhou M, Dong X, Qu J, Gong F, Han Y, et al. Epidemiological and clinical characteristics of 99 cases of 2019 novel coronavirus pneumonia in Wuhan, China: a descriptive study. The Lancet. 2020;395(10223):507-13 